\title{
Engineering the surface pattern of microparticles: from raspberry-like to golf ball-like
}

Di Han ${ }^{1, \dagger}$ Dai-Lin Zhou, ${ }^{1, \dagger}$ Qing-Yun Guo, ${ }^{2}$ Xiong Lin, ${ }^{1}$ Qin Zhang, ${ }^{1}$ Qiang Fu ${ }^{1, *}$

1. College of Polymer Science \& Engineering, State Key Laboratory of Polymer Materials

Engineering, Sichuan University, Chengdu, 610065, P. R. China.

2. South China Advanced Institute for Soft Matter Science and Technology, School of Molecular Science and Engineering, South China University of Technology, Guangzhou, 510640, P. R. China.

* Corresponding author: E-mail: qiangfu@scu.edu.cn

$\dagger$ These authors contributed equally to this work.
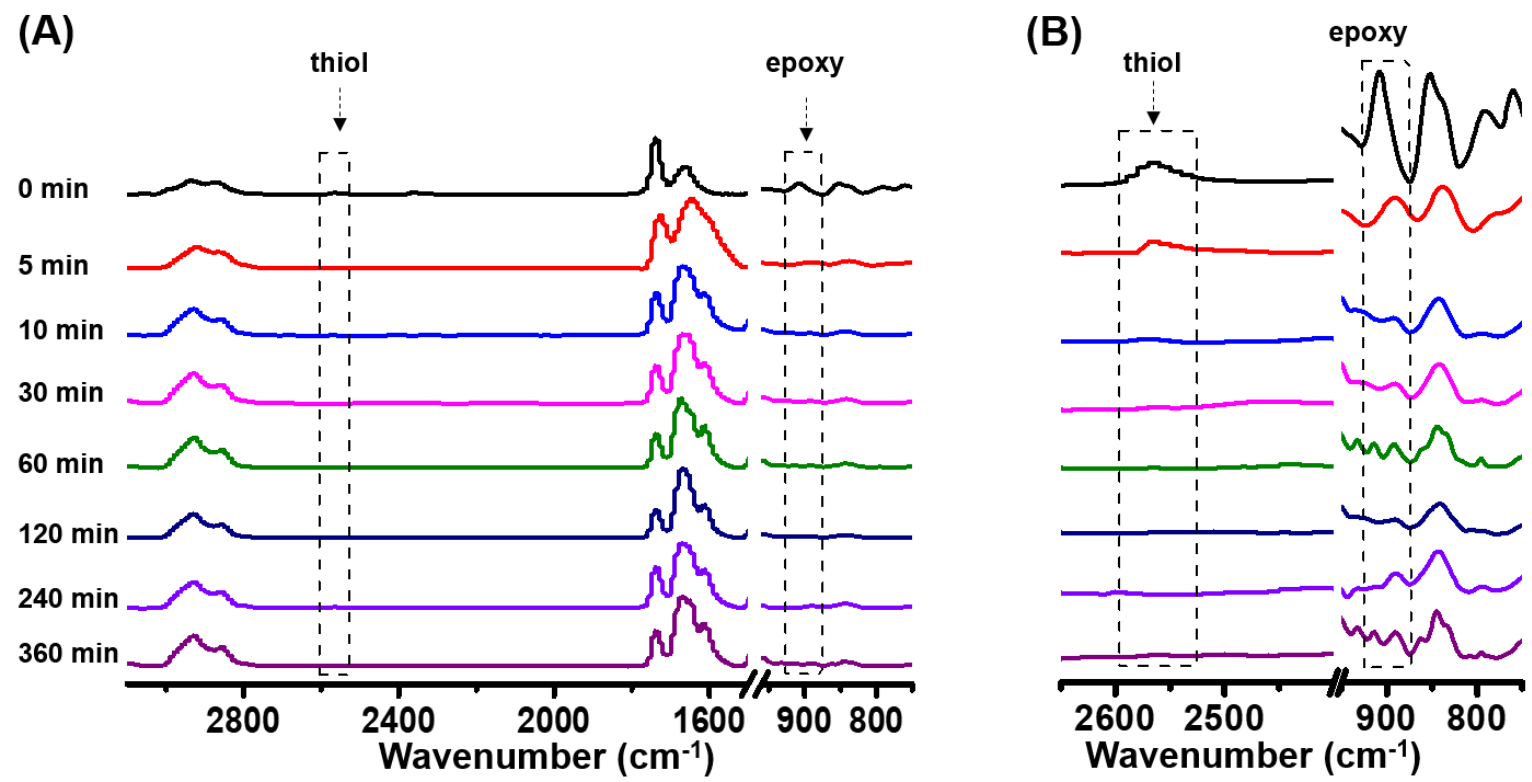

Figure S1. The kinetic of the raspberry-like microparticles formation analysis by FT-IR spectra. (A) The entire spectra, (B) the enlarged spectra region of thiol and epoxy groups. Polymerization conditions: stoichiometry of 1:1 mixture of thiol: epoxy groups (molar ratio of PETMP:GPOSS = 2:1) with $13 \mathrm{mg} / \mathrm{mL}$ monomer concentration in $100 \mathrm{~mL}$ isopropanol with $1.0 \mathrm{~g}$ PVP and $1.5 \mathrm{~mL}$ DBU, the solution mixture was stirred at room temperature for $6 \mathrm{~h}$. 
Table S1. Detailed experimental conditions for the synthesis raspberry-like microparticles with controllable morphologies.

\begin{tabular}{|c|c|c|c|c|c|c|c|c|c|c|}
\hline & $\begin{array}{c}\text { GPO } \\
\text { SS/ } \\
\mathrm{g}\end{array}$ & $\begin{array}{l}\text { PETMP/ } \\
\mathrm{g}\end{array}$ & $\begin{array}{l}\text { DBU } \\
\text { loading/ } \\
\mathrm{mL}\end{array}$ & $\begin{array}{c}\text { PVP } \\
\text { concentration }^{a} / \\
\mathrm{mg} / \mathrm{mL}\end{array}$ & $\begin{array}{c}\text { Monomer } \\
\text { concentration }^{b /} \\
\mathrm{mg} / \mathrm{mL}\end{array}$ & $\begin{array}{c}\text { Molar ratio of } \\
\text { PETMP:GPOS } \\
\text { S }\end{array}$ & $\begin{array}{c}\text { Diameter } c / \\
\mu \mathrm{m}\end{array}$ & $\begin{array}{c}\mathrm{CV}^{d /} \\
\%\end{array}$ & $\begin{array}{c}\text { Surface } \\
\text { protrusion } \\
\text { size }^{e} \\
\mathrm{~nm}\end{array}$ & $\begin{array}{c}\text { Yield/ } \\
\%\end{array}$ \\
\hline Run 1 & 0.75 & 0.55 & 0.5 & 10 & 13 & $2: 1$ & $2.02 \pm 0.34$ & 16.76 & $372 \pm 42$ & 85.8 \\
\hline Run 2 & 0.75 & 0.55 & 1.0 & 10 & 13 & $2: 1$ & $1.62 \pm 0.14$ & 8.92 & $393 \pm 55$ & 90.6 \\
\hline Run 3 & 0.75 & 0.55 & 1.5 & 10 & 13 & $2: 1$ & $1.08 \pm 0.10$ & 9.33 & $243 \pm 33$ & 87.2 \\
\hline Run 4 & 0.75 & 0.55 & 2.5 & 10 & 13 & $2: 1$ & $1.13 \pm 0.10$ & 8.63 & $242 \pm 38$ & 86.4 \\
\hline Run 5 & 0.75 & 0.55 & 5.0 & 10 & 13 & $2: 1$ & $1.12 \pm 0.12$ & 11.02 & $191 \pm 28$ & 87.1 \\
\hline Run 6 & 0.75 & 0.55 & 1.5 & 5 & 13 & $2: 1$ & $1.08 \pm 0.24$ & 22.32 & $274 \pm 36$ & 88.5 \\
\hline Run 7 & 0.75 & 0.55 & 1.5 & 20 & 13 & $2: 1$ & $0.91 \pm 0.09$ & 9.68 & $180 \pm 22$ & 85.8 \\
\hline Run 8 & 0.75 & 0.55 & 1.5 & 30 & 13 & $2: 1$ & $1.10 \pm 0.11$ & 10.00 & $172 \pm 25$ & 88.8 \\
\hline Run 9 & 1.5 & 1.10 & 1.5 & 10 & 26 & $2: 1$ & $1.43 \pm 0.17$ & 11.64 & $343 \pm 53$ & 85.4 \\
\hline Run 10 & 0.37 & 0.28 & 1.5 & 10 & 6.5 & $2: 1$ & $0.86 \pm 0.12$ & 14.22 & $161 \pm 17$ & 90.1 \\
\hline Run 11 & 0.19 & 0.14 & 1.5 & 10 & 3.3 & $2: 1$ & $0.73 \pm 0.08$ & 11.09 & - & 90.1 \\
\hline Run 12 & 0.10 & 0.07 & 1.5 & 10 & 1.7 & $2: 1$ & $0.68 \pm 0.07$ & 10.10 & - & 89.5 \\
\hline Run 13 & 0.75 & 0.25 & 1.5 & 10 & 10 & $1: 1$ & $1.06 \pm 0.13$ & 11.95 & - & 87.6 \\
\hline Run 14 & 0.75 & 0.41 & 1.5 & 10 & 11.6 & $1.5: 1$ & $0.99 \pm 0.14$ & 14.06 & $146 \pm 20$ & 85.9 \\
\hline Run 15 & 0.75 & 0.69 & 1.5 & 10 & 14.4 & $2.5: 1$ & $1.14 \pm 0.12$ & 10.05 & $377 \pm 49$ & 87.8 \\
\hline Run 16 & 0.75 & 0.82 & 1.5 & 10 & 15.7 & $3: 1$ & $1.13 \pm 0.12$ & 10.74 & $405 \pm 51$ & 83.5 \\
\hline
\end{tabular}

${ }^{a}$ PVP concentration in isopropanol, ${ }^{b}$ monomer (PETMP and GPOSS) concentration in isopropanol, ${ }^{c}$ average particle diameters statistic from SEM images, ${ }^{d}$ coefficient of variance $(\mathrm{CV})$ statistic from SEM images. ${ }^{e}$ average surface protrusion size statistic from SEM images. The isopropanol volume was fixed on $100 \mathrm{~mL}$ and the reaction time was controlled at $6 \mathrm{~h}$ for each polymerization. 

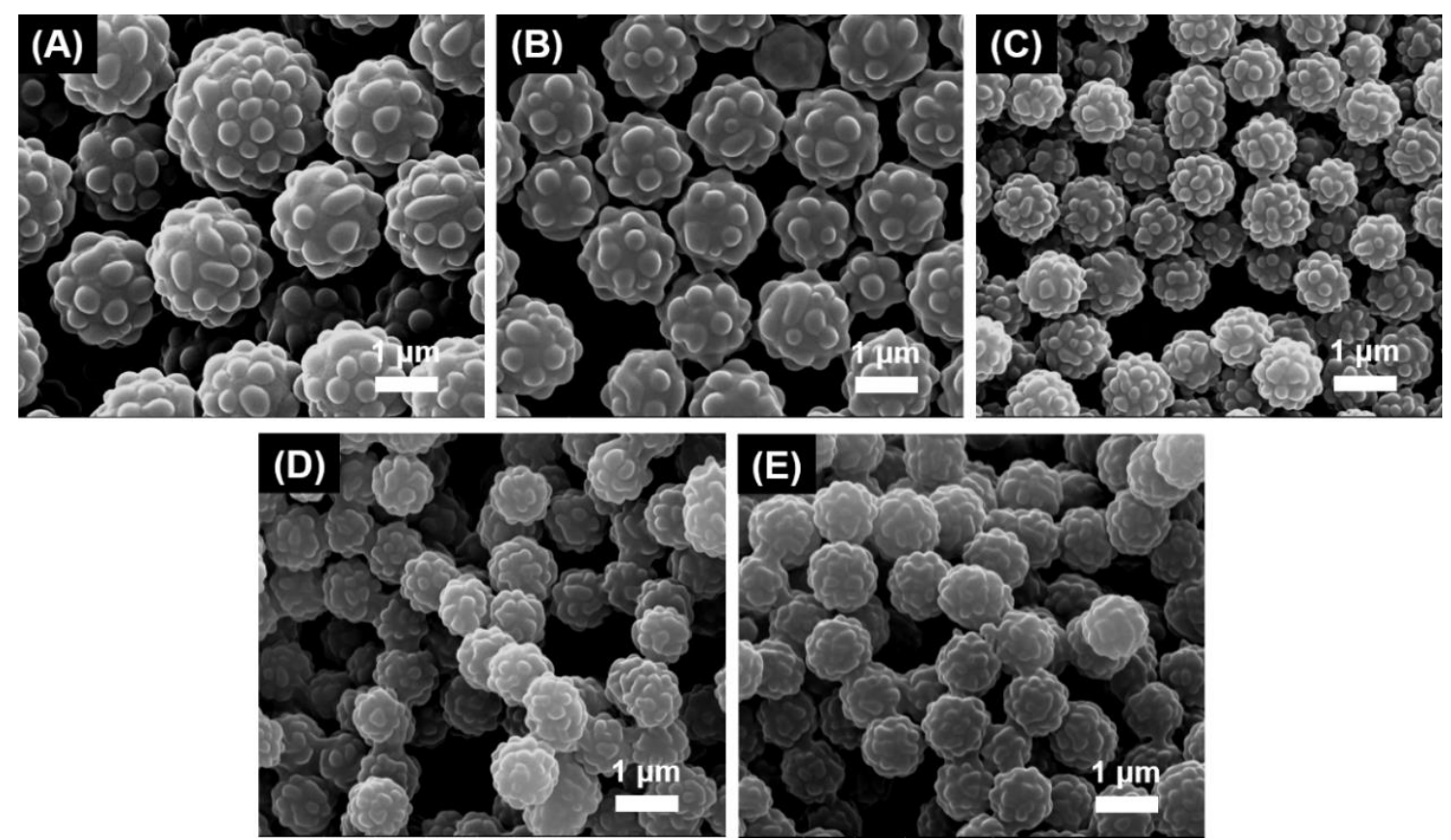

Figure S2. The morphology of particles prepared from polymerization of stoichiometry of 1:1 mixture of epoxy: thiol groups (PETMP:GPOSS = 2:1) in isopropanol with varied DBU loading. (A) 0.15, (B) 0.5 , (C) 1.5 , (D) 2.5, (E) $5 \mathrm{~mL}$. Polymerization conditions: $13 \mathrm{mg} / \mathrm{mL}$ of monomer concentration in $100 \mathrm{~mL}$ isopropanol, $1 \mathrm{~g}$ PVP, the solution mixture was stirred at room temperature for $6 \mathrm{~h}$.
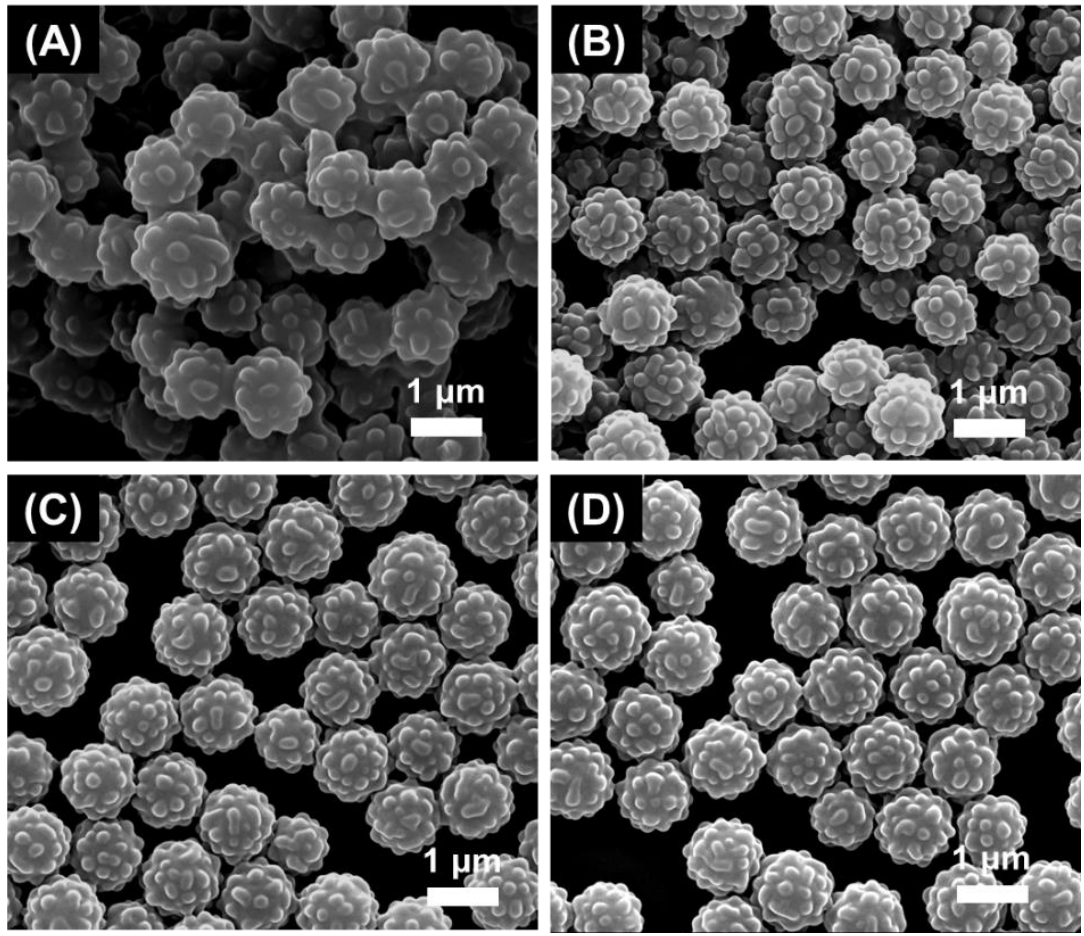

Figure S3. The morphology of particles prepared from polymerization of stoichiometry of 1:1 mixture of epoxy: thiol groups (PETMP:GPOSS $=2: 1$ ) in isopropanol with varied PVP concentration: (A) $5 \mathrm{mg} / \mathrm{mL}$, (B) $10 \mathrm{mg} / \mathrm{mL}$, (C) $20 \mathrm{mg} / \mathrm{mL}$, and (D) $30 \mathrm{mg} / \mathrm{mL}$ of PVP in isopropanol. Polymerization conditions: $13 \mathrm{mg} / \mathrm{mL}$ of monomer concentration in $100 \mathrm{~mL}$ isopropanol, $1.5 \mathrm{~mL} \mathrm{DBU}$, the solution mixture was stirred at room temperature for $6 \mathrm{~h}$. 

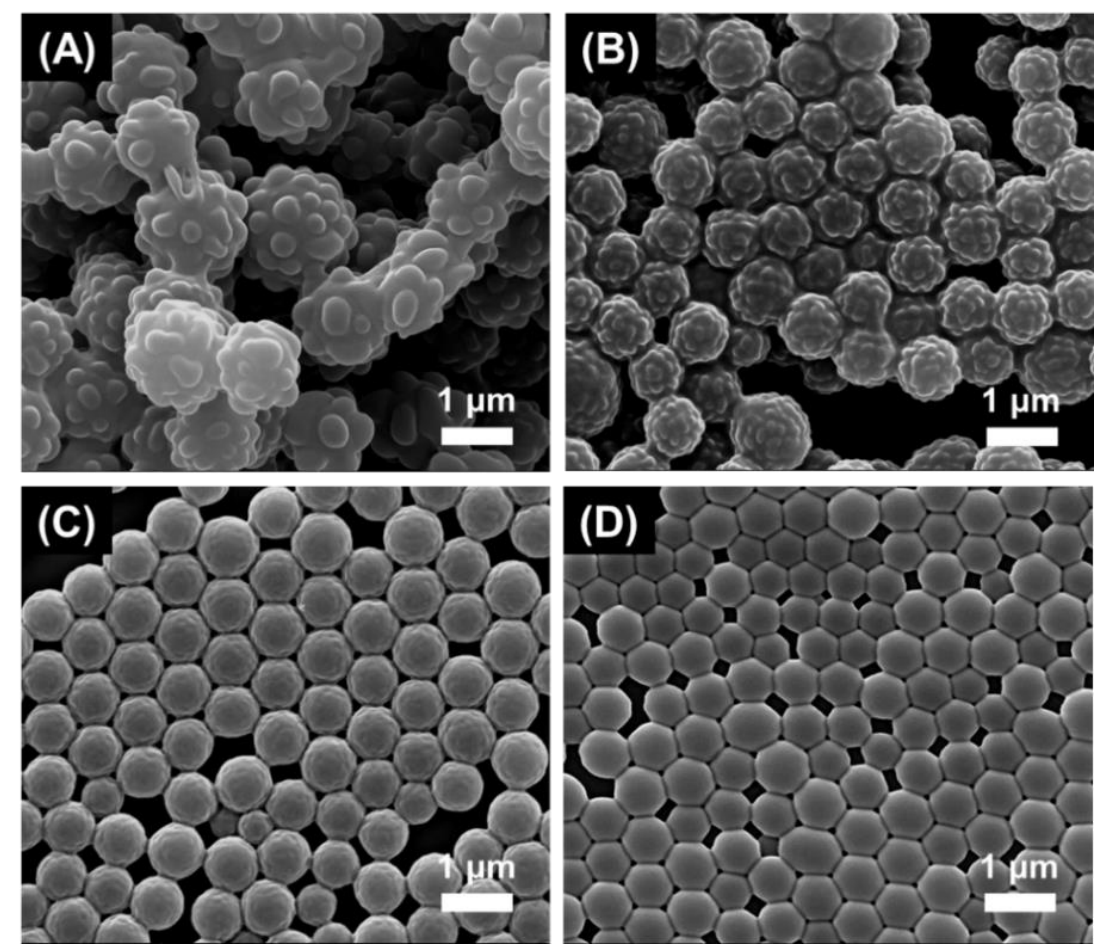

Figure S4. The morphology of particles prepared from polymerization of stoichiometry of 1:1 mixture of epoxy: thiol groups (PETMP:GPOSS $=2: 1$ ) in isopropanol with varied monomer concentrations. (A) 26, (B) 6.5, and (C) 3.3, (D) $1.7 \mathrm{mg} / \mathrm{mL}$ of monomer in isopropanol. Polymerization conditions: $1.5 \mathrm{~mL}$ DBU, $1 \mathrm{~g}$ PVP, $100 \mathrm{~mL}$ isopropanol, the solution mixture was stirred at room temperature for $6 \mathrm{~h}$.
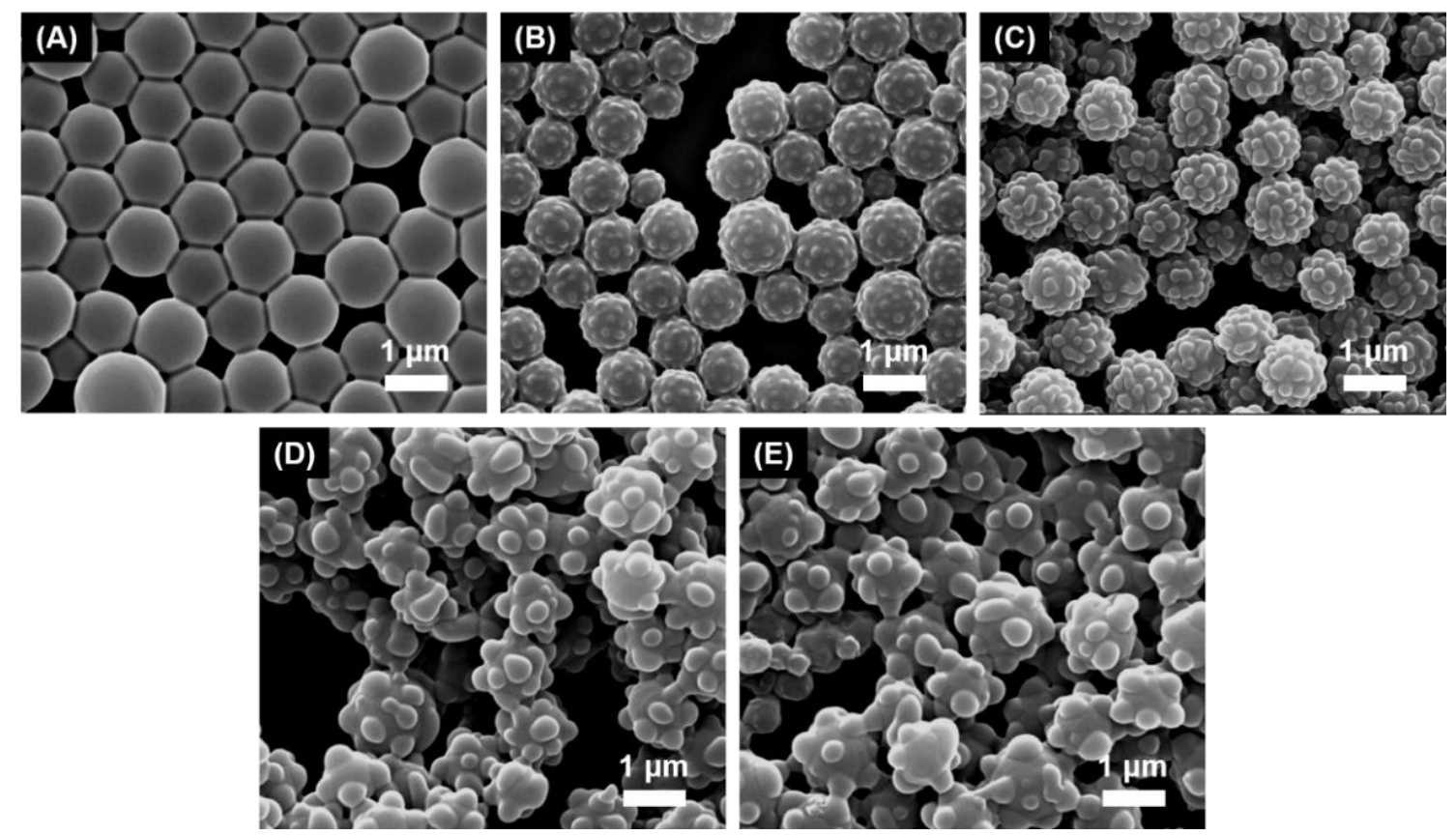

Figure S5. The morphology of particles prepared from polymerization of PETMP and GPOSS with the molar ratios of (A) 1:1, (B) 1.5:1, (C) 2:1, (D) 2.5:1, (E) 3:1. Polymerization conditions: $0.75 \mathrm{~g}$ GPOSS, $1.5 \mathrm{~mL}$ DBU, $1.0 \mathrm{~g}$ PVP, and $100 \mathrm{~mL}$ isopropanol, the solution mixture was stirred at room temperature for $6 \mathrm{~h}$. 


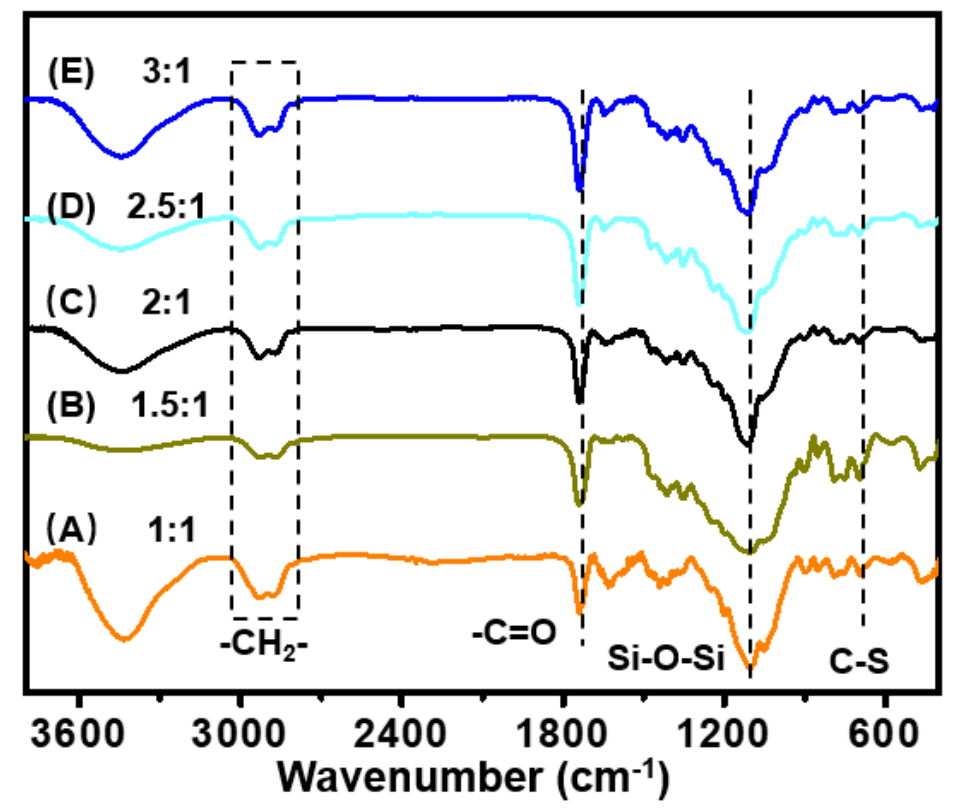

Figure S6. FT-IR spectra of raspberry-like microparticles prepared from polymerization of PETMP and GPOSS with the molar ratios of (A) 1:1, (B) 1.5:1, (C) 2:1, (D) 2.5:1, (E) 3:1.

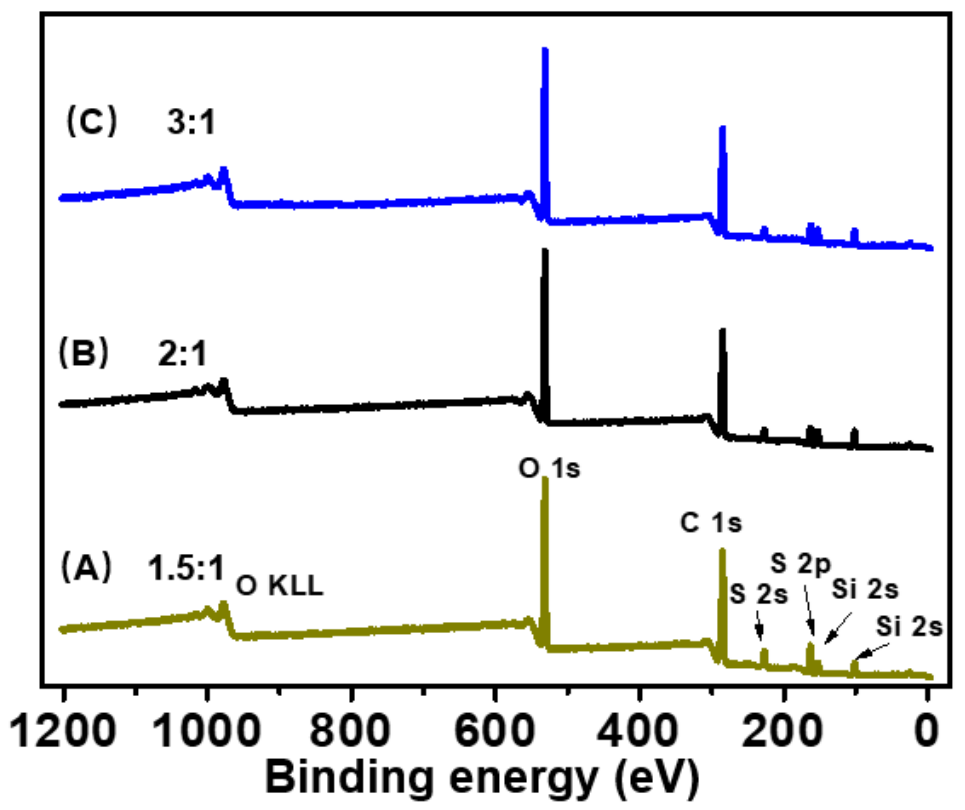

Figure S7. XPS spectra of raspberry-like microparticles prepared from polymerization of PETMP and GPOSS with the molar ratios of (A) 1.5:1, (B) 2:1, (C) 3:1. 
Table S2. Relative elemental content of raspberry-like microparticles obtained from monomer feeding ratio and XPS results.

$\mathrm{C}(\%)$

$\mathrm{Si}(\%)$

$\mathrm{O}(\%)$

$\mathrm{S}(\%)$

PETMP/GPOSS

calculated/found

calculated/found

calculated/found

calculated/found

$1.5: 1$

$2: 1$

$3: 1$
$57.65 / 60.06$

$57.75 / 59.71$

$57.89 / 60.01$
$6.27 / 7.13$

$5.63 / 7.83$

$4.68 / 5.29$
$31.37 / 28.88$

$30.99 / 28.18$

$30.41 / 27.49$
4.71/3.93

$5.64 / 4.28$

$7.02 / 7.21$

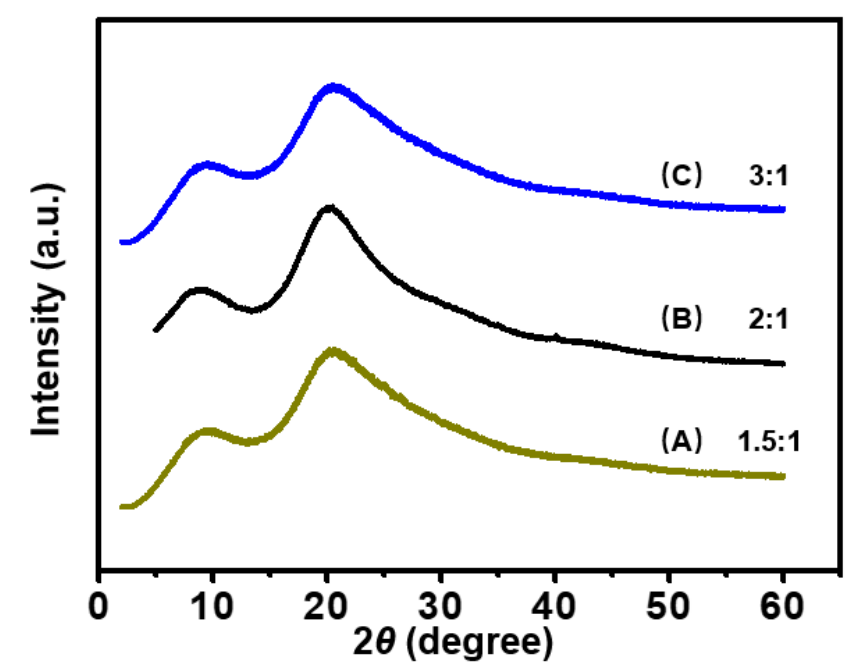

Figure S8. WAXD patterns of raspberry-like particles prepared from polymerization of PETMP and GPOSS with the molar ratios of (A) 1.5:1, (B) 2:1, (C) 3:1.

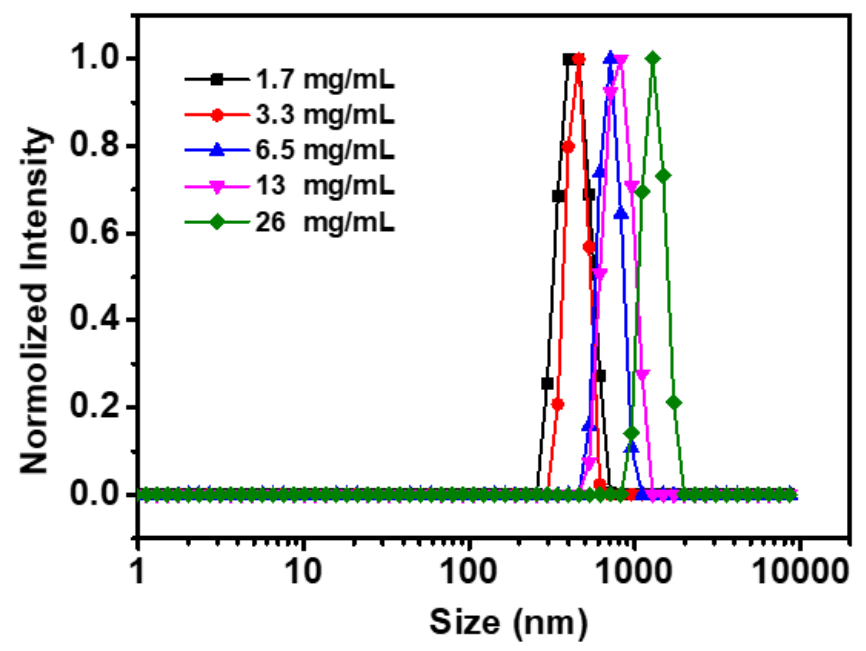

Figure S9. DLS results of different monomer concentration (molar ratio of PETMP:GPOSS $=2: 1$ ) in $100 \mathrm{~mL}$ isopropanol with the presence of $1 \mathrm{~g}$ PVP. 

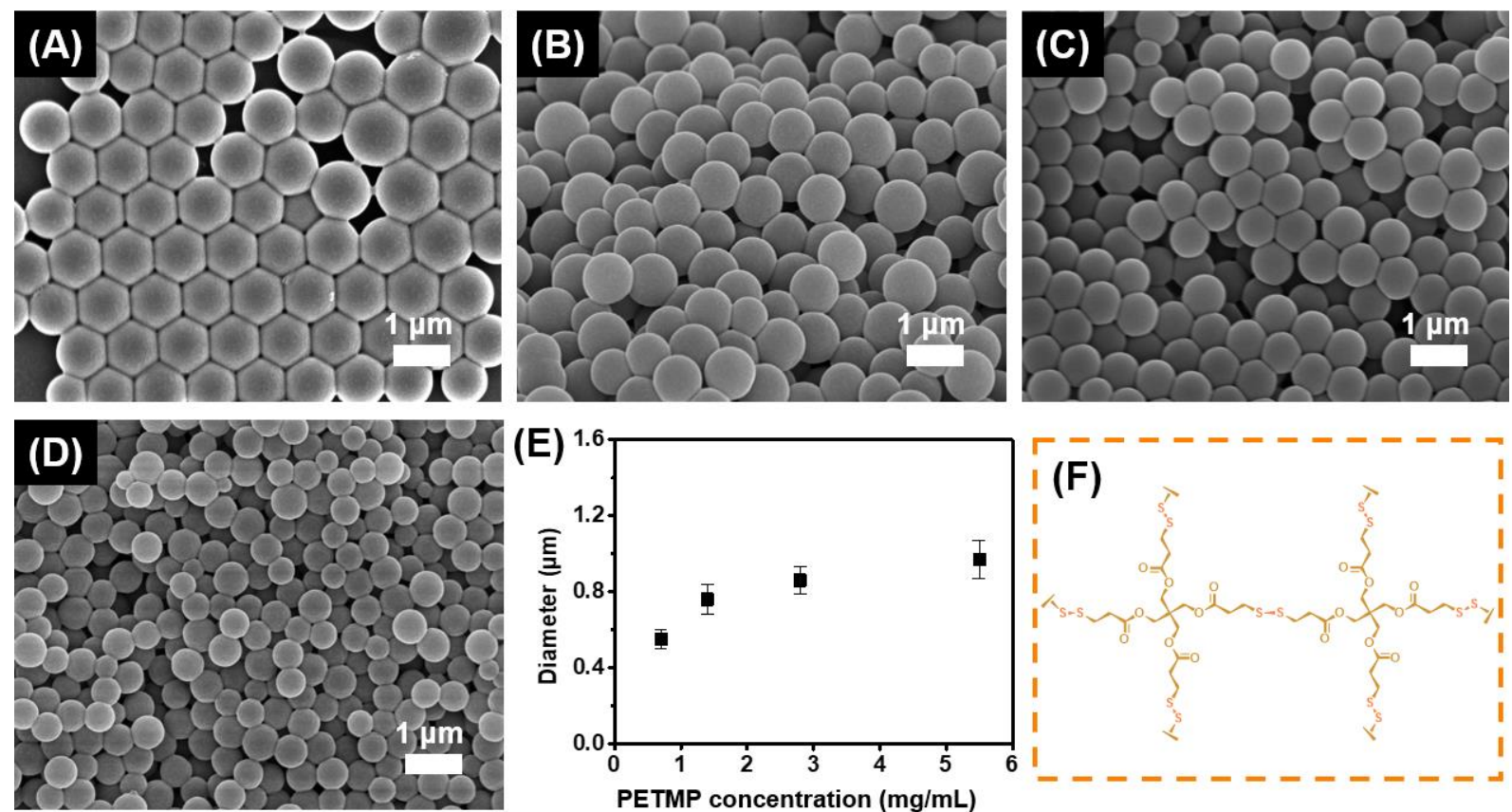

Figure S10. SEM images of disulfide particles prepared from the PETMP concentration of (A) 5.5 $\mathrm{mg} / \mathrm{mL}$, (B) $2.75 \mathrm{mg} / \mathrm{mL}$, (C) $1.4 \mathrm{mg} / \mathrm{mL}$, (D) $0.7 \mathrm{mg} / \mathrm{mL}$. Polymerization condition: $1.5 \mathrm{~mL}$ DBU, $1.0 \mathrm{~g}$ PVP, and $100 \mathrm{~mL}$ isopropanol. (E) Their corresponding average diameters. (F) Chemical structure of disulfide network.

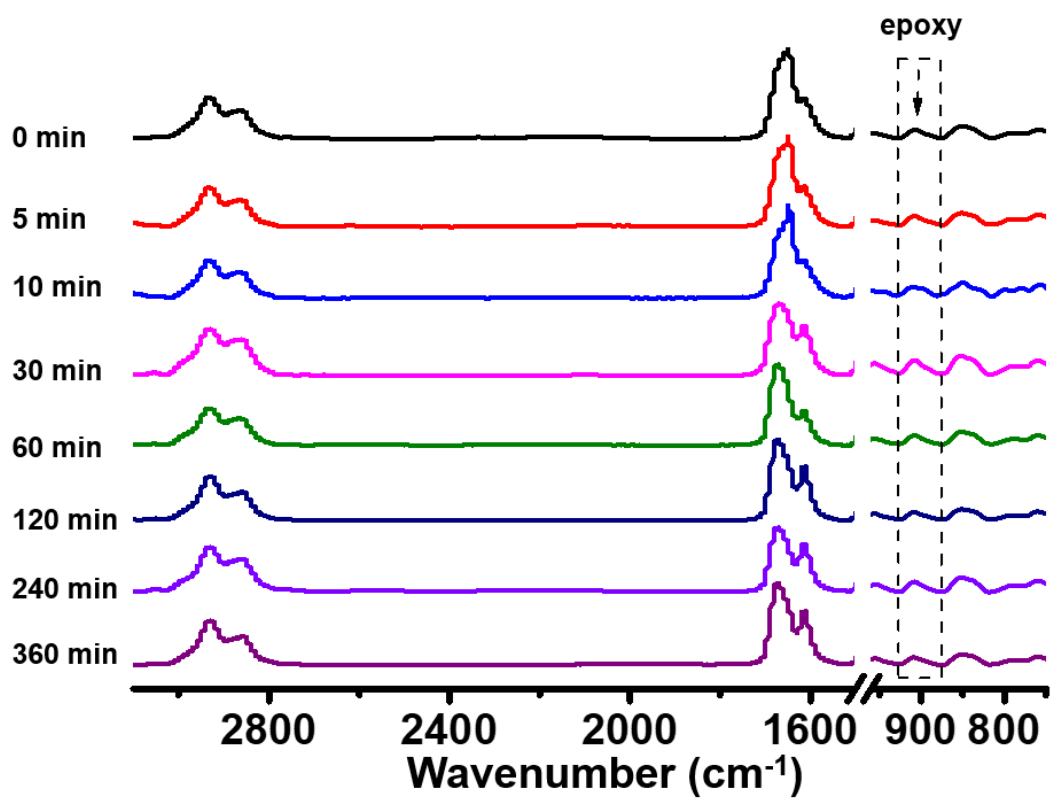

Figure S11. The kinetic of the GPOSS droplets analysis by FT-IR spectra. Reaction conditions: 0.65 g GPOSS and $1.0 \mathrm{~g}$ PVP in $100 \mathrm{~mL}$ isopropanol with $1.5 \mathrm{~mL} \mathrm{DBU}$, the solution mixture was stirred at room temperature for $6 \mathrm{~h}$. 

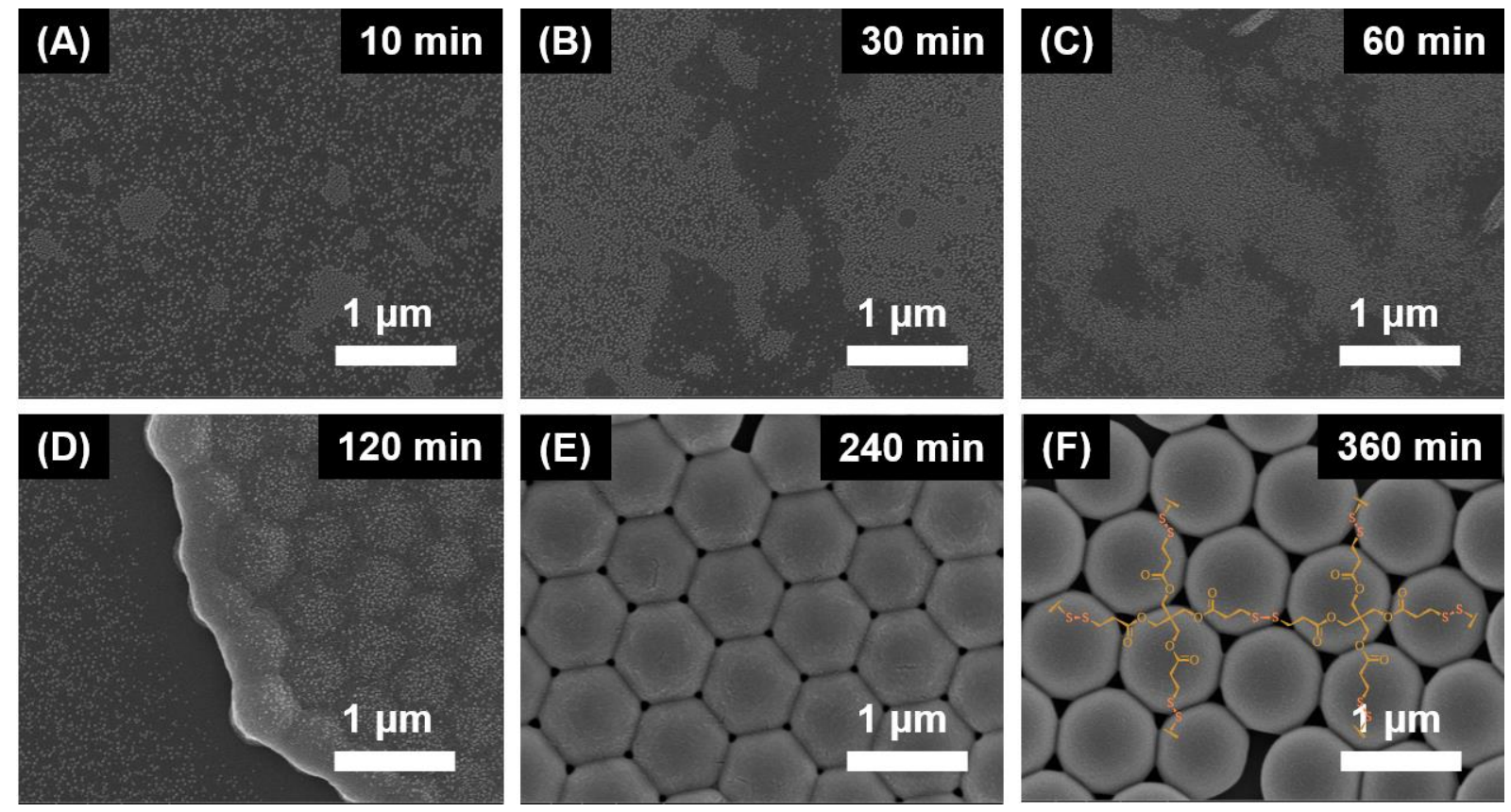

Figure S12. SEM images of disulfide particles at different reaction time. (A) 10, (B) 30, (C) 60, (D) 120, (E) 240, and (F) $360 \mathrm{~min}$. Polymerization condition: $5.5 \mathrm{mg} / \mathrm{mL}$ PETMP in $100 \mathrm{~mL}$ isopropanol, $1.5 \mathrm{~mL}$ DBU, $1 \mathrm{~g}$ PVP. The solution mixture was quenched by acetic acid and washed with isopropanol for three times before SEM observation.
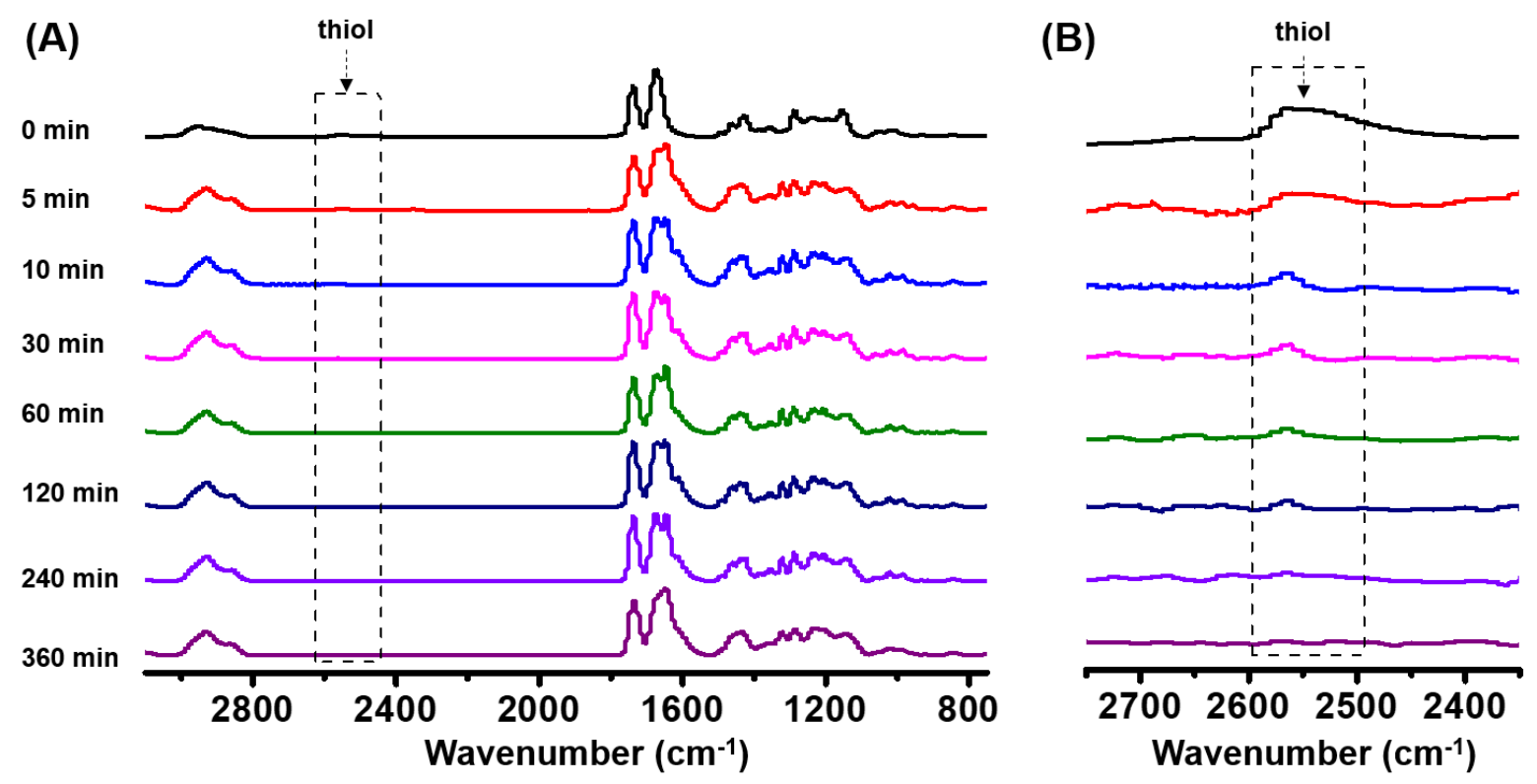

Figure S13. The kinetic of the disulfide particles formation analysis by FT-IR spectra. (A) The entire spectra, (B) the enlarged spectra region of thiol group. Reaction conditions: $0.55 \mathrm{~g}$ PETMP and $1.0 \mathrm{~g}$ PVP in $100 \mathrm{~mL}$ isopropanol with $1.5 \mathrm{~mL}$ DBU, the solution mixture was stirred at room temperature for $6 \mathrm{~h}$. 


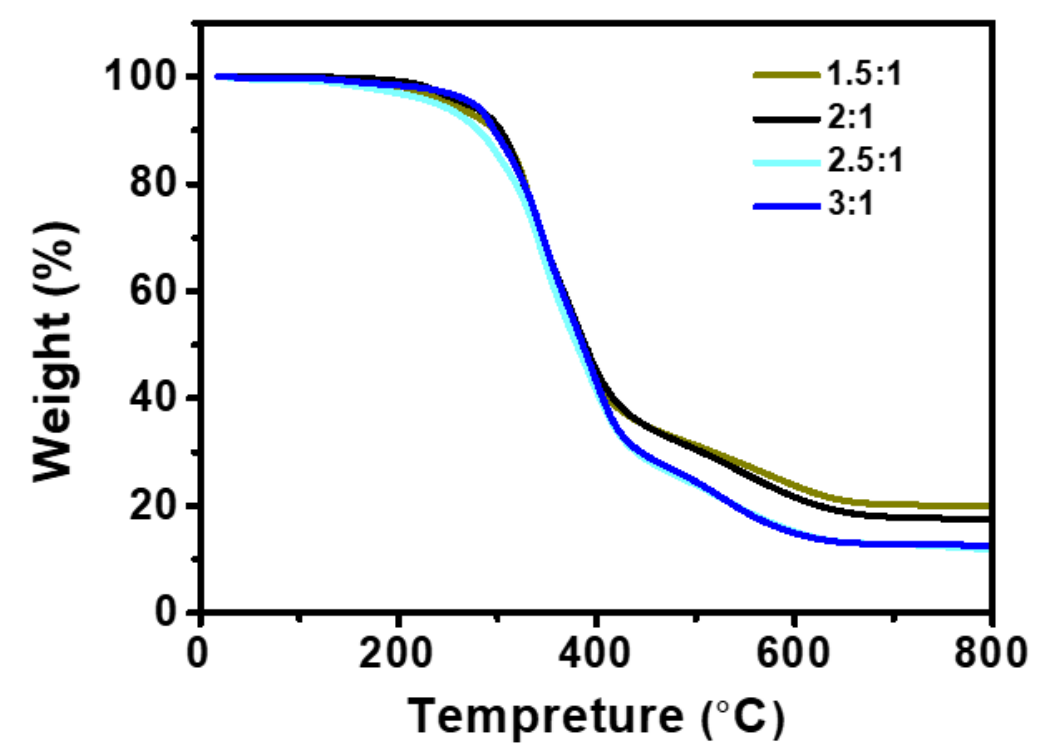

Figure S14. TGA curves of raspberry-like of microparticles prepared from polymerization of PETMP and GPOSS with the molar ratios of 1.5:1, 2:1, 2.5:1 and 3:1.
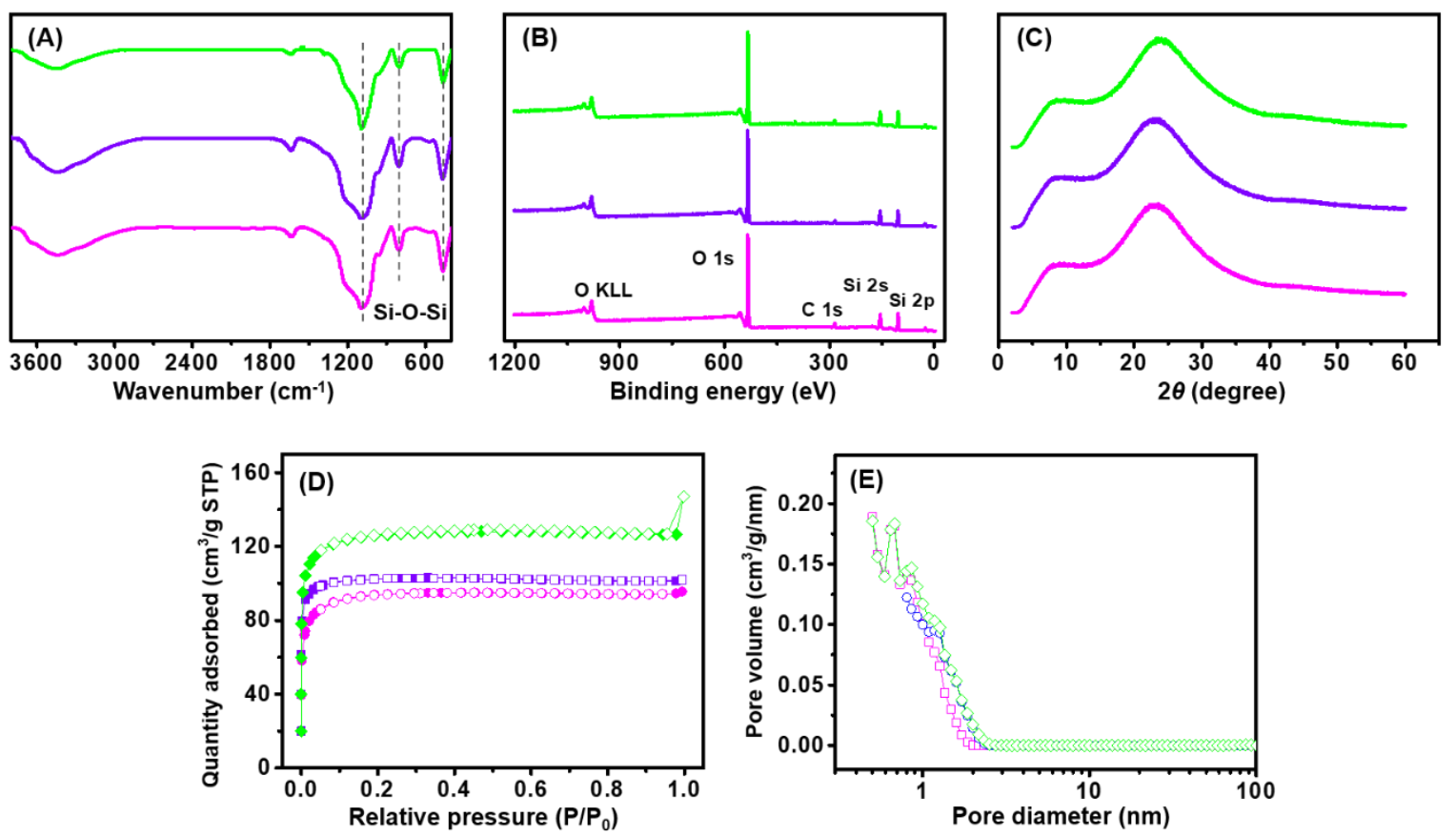

Figure S15. (A) FT-IR, (B) XPS, (C) WAXD, (D) nitrogen adsorption (closed symbols) and desorption (open symbols) isotherms and (E) pore size distribution curves of golf ball-like (sub)microparticles. Their raspberry-like particle precursors were prepared from polymerization of PETMP and GPOSS with the molar ratios of 1.5:1 (magenta line), 2:1 (violet line), and 3:1 (green line). 
Table S3. Relative elemental content of golf ball-like (sub)microparticles obtained from XPS results. Their raspberry-like particle precursors were prepared from polymerization of PETMP and GPOSS with the molar ratios of $1.5: 1,2: 1$, and $3: 1$.

\begin{tabular}{ccccc}
\hline $\begin{array}{c}\text { Molar ratio of } \\
\text { PETMP:GPOSS }\end{array}$ & $\mathrm{C}(\%)$ & $\mathrm{Si}(\%)$ & $\mathrm{O}(\%)$ & $\mathrm{S}(\%)$ \\
\hline $1.5: 1$ & 8.59 & 38.29 & 53.11 & 0 \\
$2: 1$ & 5.17 & 39.09 & 55.74 & 0 \\
$3: 1$ & 8.38 & 38.99 & 52.63 & 0 \\
\hline
\end{tabular}

Table S4. Porosity data of golf ball-like (sub)microparticles. Their raspberry-like particle precursors were prepared from polymerization of PETMP and GPOSS with the molar ratios of 1.5:1, 2:1, and 3:1.

Molar ratio of

PETMP:GPOSS

$$
S_{\text {BET }}\left(\mathrm{m}^{2} / \mathrm{g}\right)^{a} \quad V_{\text {pore }}\left(\mathrm{cm}^{3} / \mathrm{g}\right)^{b} \quad D_{\text {pore }}(\mathrm{nm})^{c}
$$
$1.5: 1$
314.0
0.16
2.0

$2: 1$

291.3

0.15

2.0

$3: 1$

389.8

0.23

2.3

${ }^{a}$ Surface area calculated from the $\mathrm{N}_{2}$ isotherms based on the BET method. ${ }^{b}$ Total pore volume at $P / P_{0}=0.990 .{ }^{c}$ Average pore diameters obtained from the DFT method. 

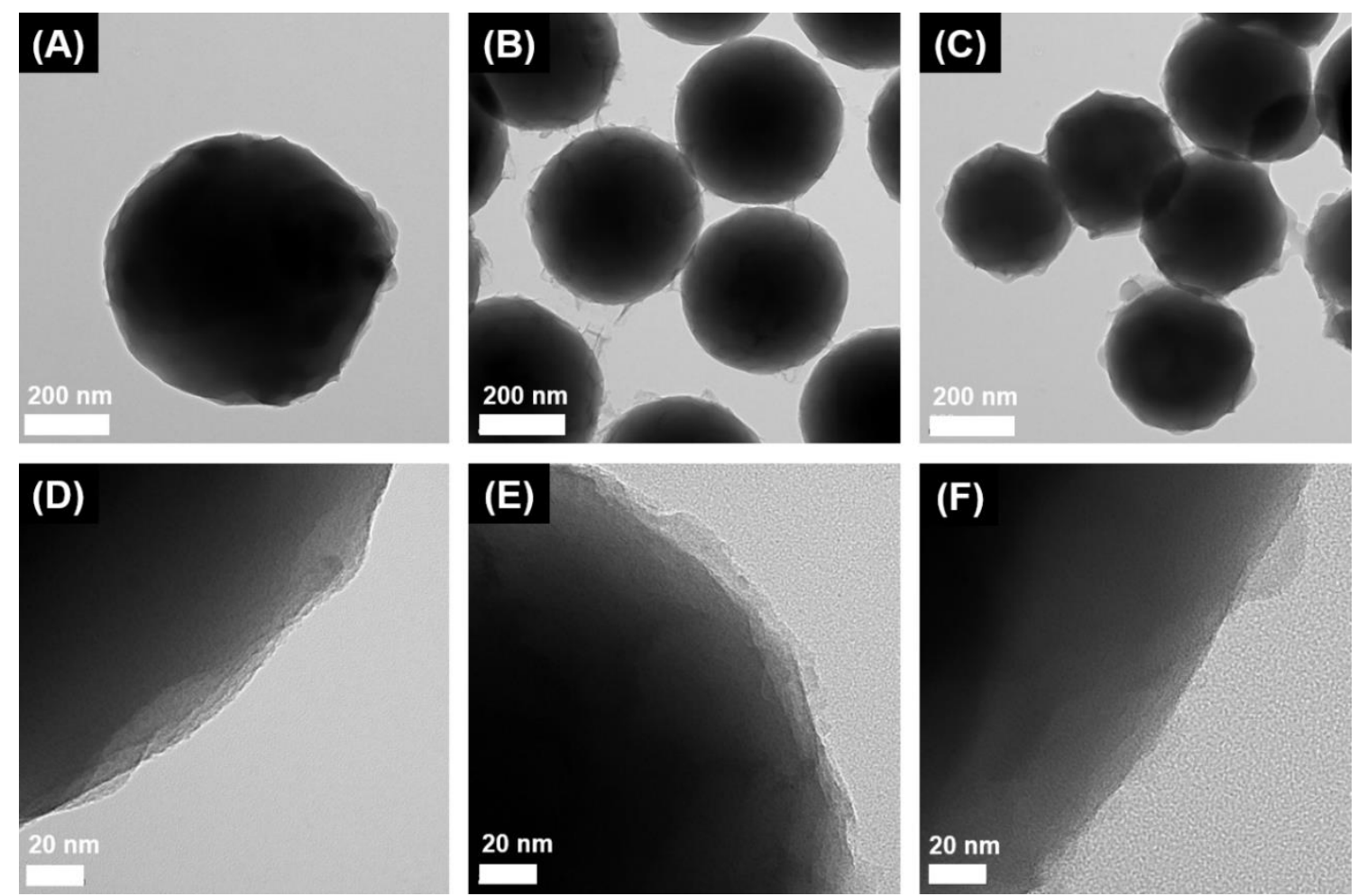

Figure S16. TEM images of golf ball-like (sub)microparticles. Their raspberry-like particle precursors were prepared from thiol-epoxy dispersion polymerization with the molar ratios of PETMP:GPOSS of (A) 1.5:1, (B) 2:1, and (C) 3:1. (D), (E) and (F) are their corresponding high-magnification images. 